\title{
Acoustic Performance of Pre-Finished Steel Buildings
}

\author{
Hanyu Leng ${ }^{1, ~ a, ~ J i a n ~ G o n g ~}{ }^{2, b}$ and Fanchang Kong ${ }^{3, c}$ \\ 1 17/F, Shuisong Building, Tairan 8th Road, Futian District, Shenzhen, Guangdong Province China \\ 2 17/F, Shuisong Building, Tairan 8th Road, Futian District, Shenzhen, Guangdong Province China \\ 3 17/F, Shuisong Building, Tairan 8th Road, Futian District, Shenzhen, Guangdong Province China \\ alenryc@foxmail.com, b397341643@qq.com, c596380638@qq.com
}

\begin{abstract}
Keywords: Acoustic Performance, Airborne Sound, Sound Insulation, Pre-Finished building, Steel Structure, Wall, ALC Broad.

Abstract. The sound that travels into and out of an enclosure space is one of the most important considerations for buildings. Generally, some forms of acoustic control are needed to meet the specifications for different types of buildings. As for pre-finished steel buildings, great efforts are made on the details of building components, i.e. walls and frames, to improving the acoustic performance. This article contains the results of a series of acoustical tests carried out in a completed building with Tianjin University, an analysis of acoustic performance of pre-finished steel structure building components and guidance on detailing of walls and frames, aiming to help designers, architects, researchers and construction professionals to achieve the optimum acoustic performance of their works.
\end{abstract}

\section{Introduction}

Sound is produced by vibration of objects, which is called sound source, and the two major characteristics of sound are the loudness and frequency [1]. The loudness is expressed in decibels $(\mathrm{dB})$ and frequency is expressed in $\operatorname{Hertz}(\mathrm{Hz})$. Sounds within the frequency range $100 \mathrm{~Hz}$ to $3150 \mathrm{~Hz}$, which can be detected by the human ears, are selected in the tests [4].

Acoustic performance of buildings usually means the ability of the envelope to insulate the airborne and impact sound [2]. With the fact that impact sound is more important for roofs and floors, this article aims on the airborne sound, which is more important for walls and frames. Sound travels by two routes, directly through the insulating structure called direct transmission and around the insulating structure through adjacent building components called flanking transmission [3]. The tests in this case are made in completed buildings in other to cover the influence of flanking transmission.

\section{Principle}

The acoustic performance of walls and frames is dependent on the mass, the stiffness, the isolation and the surface finish [2,7]. Here in the tests, the sealing around the edge of the components is assumed to be in the same construction quality.

The acoustic requirements of civil buildings are normally given in GB 50118-2010 in China. $\mathrm{D}_{\mathrm{nTw}}$, $\mathrm{C}, \mathrm{C}_{\mathrm{tr}}, \mathrm{R}_{\mathrm{w}}$ are units of measurement to express the airborne acoustic performance. $\mathrm{D}_{\mathrm{nTw}}$ is a measurement of the airborne sound insulation between two rooms achieved by on site testing and therefore includes flanking sound leakage around the separating wall. $\mathrm{C}$ is a sound spectrum adaptation factor to take account of medium and high frequency sound. $\mathrm{C}_{\mathrm{tr}}$ is a sound spectrum adaptation factor to take account of low frequency sound and is typically -6 to $-16 \mathrm{~dB}$ for light weight wall construction. $\mathrm{R}_{\mathrm{w}}$ is a measurement of the airborne sound insulation between two rooms achieved by laboratory testing and therefore does not include flanking sound leakage around the separating wall $[4,5]$.

The amount of flanking sound leakage around a separating wall depends on many factors e.g. wall construction, floor construction, junction details, quality of workmanship and room geometry. A typical value of flanking sound would be in the range of 4 to $6 \mathrm{~dB}$. We refer with the Building Bulletin 93 and the following approximate relationship between $\mathrm{R}_{\mathrm{w}}$ and $\mathrm{D}_{\mathrm{nTw}}$ are given. [4,7] 
$\mathrm{R}_{\mathrm{w}}=($ approx $) \mathrm{D}_{\mathrm{nTw}}+10 \times \log (\mathrm{S} \times \mathrm{T} / \mathrm{V})+8 \mathrm{~dB}+\mathrm{F}$

Where;

$\mathrm{S}=$ surface area of the separating wall in $\mathrm{m}^{2}$

$\mathrm{T}=$ maximum reverberation time for the room in seconds

$\mathrm{F}=$ value to allow for flanking sound in $\mathrm{dB}$

$\mathrm{V}=$ volume of the receiving room in $\mathrm{m}^{3}$.

Based on the typical values given above and room geometries, the approximations given below used in the tests:

$$
\begin{aligned}
& \mathrm{R}_{\mathrm{w}}=\mathrm{D}_{\mathrm{nTw}}{ }^{1}+5 \mathrm{~dB} \\
& \mathrm{D}_{\mathrm{nTw}}{ }^{1}=\mathrm{D}_{\mathrm{nTw}}+\mathrm{C}_{\mathrm{tr}}+\mathrm{C}+12 \mathrm{~dB} \text { (for walls) } \\
& \mathrm{D}_{\mathrm{nTw}}{ }^{1}=\mathrm{D}_{\mathrm{nTw}}+\mathrm{C}_{\mathrm{tr}}+\mathrm{C}+7 \mathrm{~dB} \text { (for frames) }
\end{aligned}
$$

\section{Testing Measurement}

We carried out a site testing on acoustic properties in a residence in Tianjin per GBJ75-84 [6]. A steady sound source with a continuous spectrum in the frequency bands intervals from $100 \mathrm{~Hz}$ to $3150 \mathrm{~Hz}$ is used and measurements are taken at octave frequency.

Figure 1. Measurement point layout plan
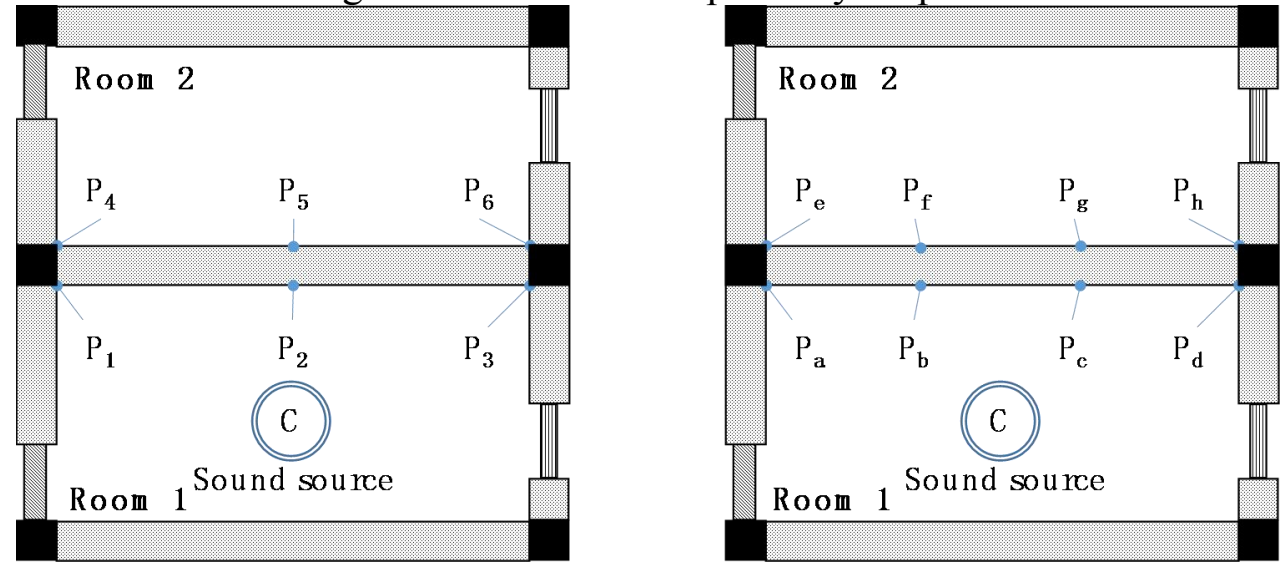

Figure 2. Measurement point layout elevation
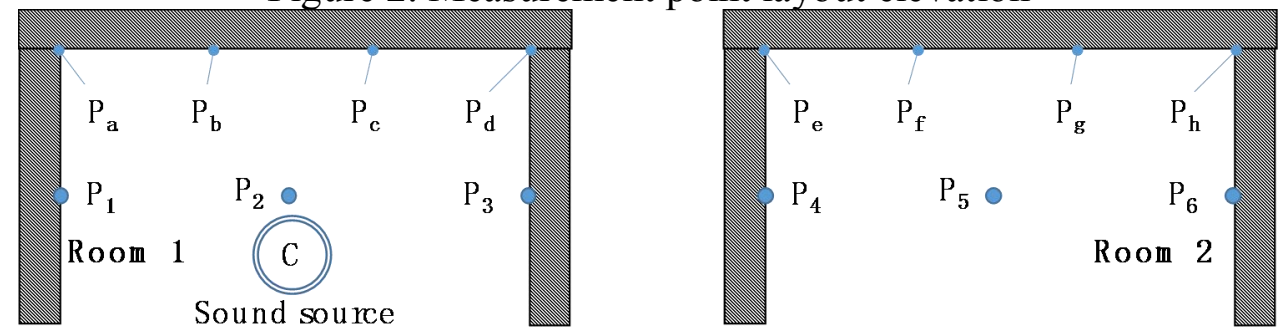

P present the measurement points, with the number subscript for walls and letters for frames. Unlike the usual sound insulation measurement scheme, we use multi-receivers and their weighted average data for analysis to cover the influence of flanking transmission.

There are six groups (shown in Table 1) with different details of walls and frames in the tests, through which we compare the acoustic performance of different structure materials, wall materials, surface finish practice and forms of acoustic control for steel frames. 
Table 1. Details of Test Groups

\begin{tabular}{|c|c|c|}
\hline Group & Details of walls & Details of frames \\
\hline 1 & $\begin{array}{c}\text { Bricks }(200 \mathrm{~mm}, \text { B06) + Double-sided Mortar } \\
(100 \mathrm{~mm})\end{array}$ & Concrete Frames \\
\hline 2 & ALC Broad (150mm, B05) & Steel Frames + ALC (50mm) \\
\hline 3 & ALC Broad (150mm, B05) & $\begin{array}{c}\text { Steel Frames }+ \text { Rock Wool }\left(15 \mathrm{~kg} / \mathrm{m}^{3}\right)+ \\
\text { Plasterboard }(5 \mathrm{~mm})\end{array}$ \\
\hline 4 & $\begin{array}{c}\text { ALC Broad (150mm, B05) + Double-sided } \\
\text { Mortar }(100 \mathrm{~mm})\end{array}$ & Steel Frames + ALC (50mm) \\
\hline 5 & $\begin{array}{c}\text { Bricks (200mm, B06) + Double-sided Mortar } \\
(100 \mathrm{~mm})\end{array}$ & $\begin{array}{l}\text { Steel Frames }+ \text { Rock Wool }\left(15 \mathrm{~kg} / \mathrm{m}^{3}\right)+ \\
\text { Plasterboard }(5 \mathrm{~mm})\end{array}$ \\
\hline 6 & $\begin{array}{c}\text { ALC Broad (200mm, B05) + Double-sided } \\
\text { Mortar (100mm) }\end{array}$ & $\begin{array}{c}\text { Steel Frames }+ \text { Rock Wool }\left(15 \mathrm{~kg} / \mathrm{m}^{3}\right)+ \\
\text { Plasterboard }(5 \mathrm{~mm})\end{array}$ \\
\hline
\end{tabular}

\section{Interpretation of Results}

The weighted average sound reduction index of all the receivers at different frequencies are shown in Table 2 and Table 3

Table 2. Sound Reduction Index in Difference Frequency

\begin{tabular}{|c|c|c|c|c|c|c|c|c|c|c|c|c|c|}
\hline \multirow[t]{2}{*}{ Group } & \multicolumn{13}{|c|}{ sound reduction index $(\mathrm{dB})$ in difference frequency $(\mathrm{Hz})$} \\
\hline & 100 & 125 & 160 & 200 & 250 & 315 & 400 & & 1250 & 1600 & 2000 & 2500 & 3150 \\
\hline 1 & 28.5 & 35.3 & 36.7 & 40.2 & 39.7 & 37.3 & 39.7 & & 51.4 & 53.2 & 53.1 & 52.4 & 49.0 \\
\hline 2 & 35.1 & 28.2 & 30.9 & 28.5 & 28.4 & 32.7 & 34.0 & . & 45.1 & 46.6 & 48.7 & 50.5 & 51.8 \\
\hline 3 & 27.8 & 23.5 & 30.2 & 31.2 & 24.7 & 30.9 & 31.3 & & 46.7 & 50.5 & 51.9 & 52.8 & 54.0 \\
\hline 4 & 33.6 & 26.5 & 33.7 & 33.1 & 34.4 & 35.5 & 35.5 & $\ldots$ & 47.6 & 48.4 & 49.8 & 48.5 & 46.3 \\
\hline 5 & 36.1 & 34.0 & 36.8 & 36.2 & 37.3 & 38.4 & 40.0 & $\ldots$ & 52.3 & 53.1 & 51.9 & 51.0 & 56.7 \\
\hline 6 & 35.6 & 34.2 & 34.8 & 37.8 & 37.9 & 37.4 & 39.0 & & 49.3 & 50.4 & 52.4 & 50.5 & 51.6 \\
\hline
\end{tabular}

Table 3. Acoustic Performance of Each Group

\begin{tabular}{|c|c|c|c||c|c|c|c|}
\hline Group & $\mathrm{R}_{\mathrm{w}}[\mathrm{dB}]$ & $\mathrm{D}_{\mathrm{nTw}}[\mathrm{dB}]$ & $\mathrm{C}_{\mathrm{tr}}[\mathrm{dB}]$ & Group & $\mathrm{R}_{\mathrm{w}}[\mathrm{dB}]$ & $\mathrm{D}_{\mathrm{nTw}}[\mathrm{dB}]$ & $\mathrm{C}_{\mathrm{tr}}[\mathrm{dB}]$ \\
\hline 1 & 48 & -2 & -5 & 4 & 42 & -2 & -4 \\
\hline 2 & 40 & -1 & -3 & 5 & 48 & -2 & -4 \\
\hline 3 & 39 & -1 & -4 & 6 & 46 & -1 & -3 \\
\hline
\end{tabular}

Comparison between Group 1 and 5. Group 1 and 5 have the same details of walls. The comparison shows the different acoustic properties of concrete frames and steel frames. From figure 3, we can tell they have almost the same acoustic performance in medium frequency region. However, concrete frames show a better sound absorption properties in low frequency region, while the steel frames, enwrapped by plasterboard and infilled with rock wool, performs better in high frequency region. This may because concrete frames have lower resonant frequency but fail in frequency near $3150 \mathrm{~Hz}$ due to the coincidence effect. Plasterboards and rock wool help a lot to reduce the effects of coincidence effect within the frequency range that humans can detect.

Figure 3. Comparison between Group 1 and 5.

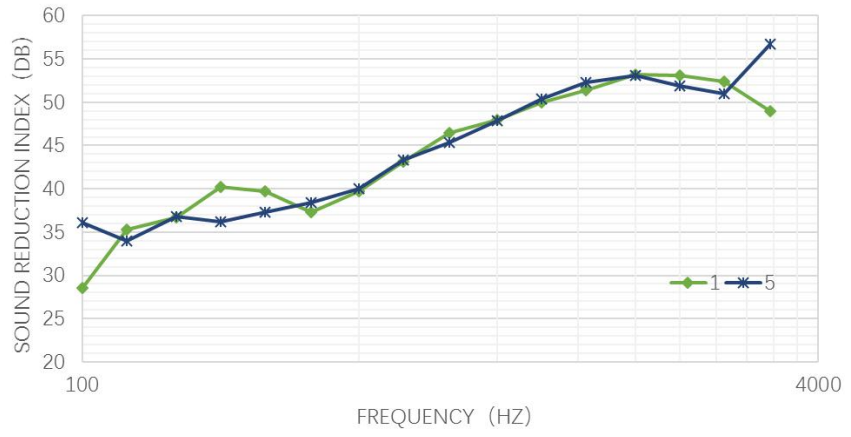


Comparison between Group 2 and 3. Group 2 and 3 have the same details of walls. The comparison shows the acoustic properties of different details of steel frames. From figure 4, we can tell they have almost the same acoustic performance in medium frequency region, while frames infilled with ALC bricks performs better in low frequency region while slightly poorer in high frequency. The multilayer construction of group 3 is the key factor that leads to the difference.

Figure 4. Comparison between Group 2 and 3.

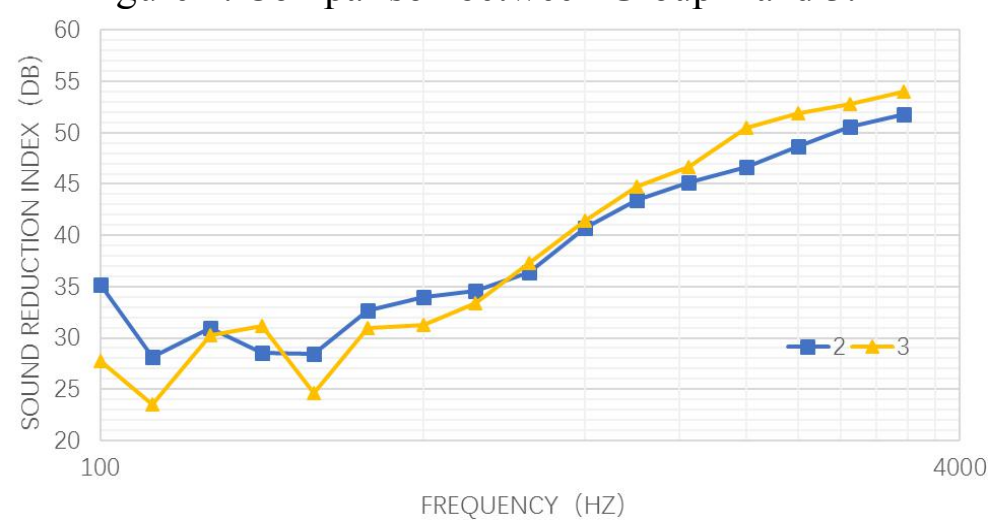

Comparison between Group 2 and 4. The comparison shows influence of double-sided mortar on ALC Broad. From figure 5, we can see a significant improvement on acoustic performance from $160 \mathrm{~Hz}$ to $2000 \mathrm{~Hz}$ after the practice of double-sided mortar is applied. And it's valuable that the practice reduces the resonant effect through lowering the second resonance frequency. But in high frequency, the result proves again that single leaf structure component is more affected by coincidence effect.

Figure 5. Comparison between Group 2 and 4.

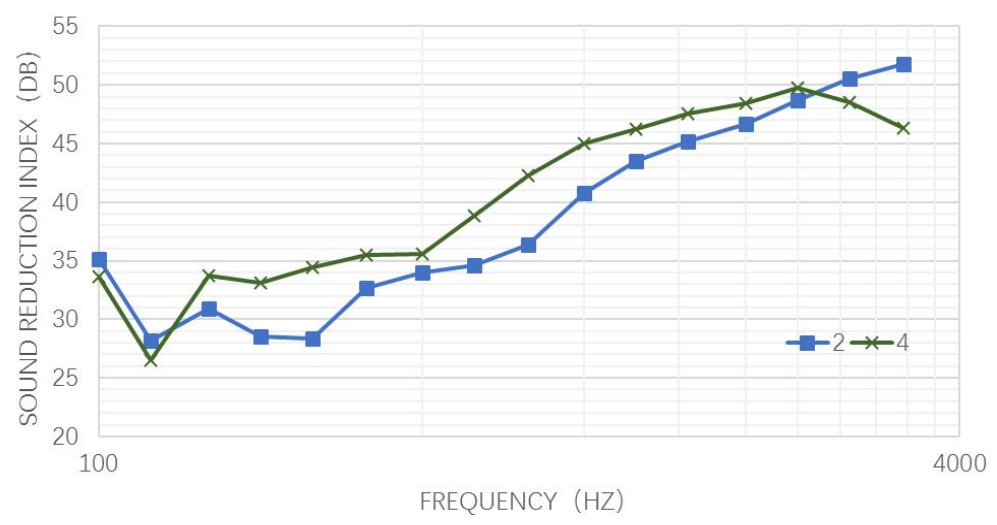

Comparison between Group 5 and 6. The comparison shows the acoustic properties of ALC broads and traditional bricks. From figure 6, we can tell there is little difference between them and bricks, which have larger mass, perform better in medium frequency region that is controlled by the mass.

Figure 6. Comparison between Group 5 and 6.

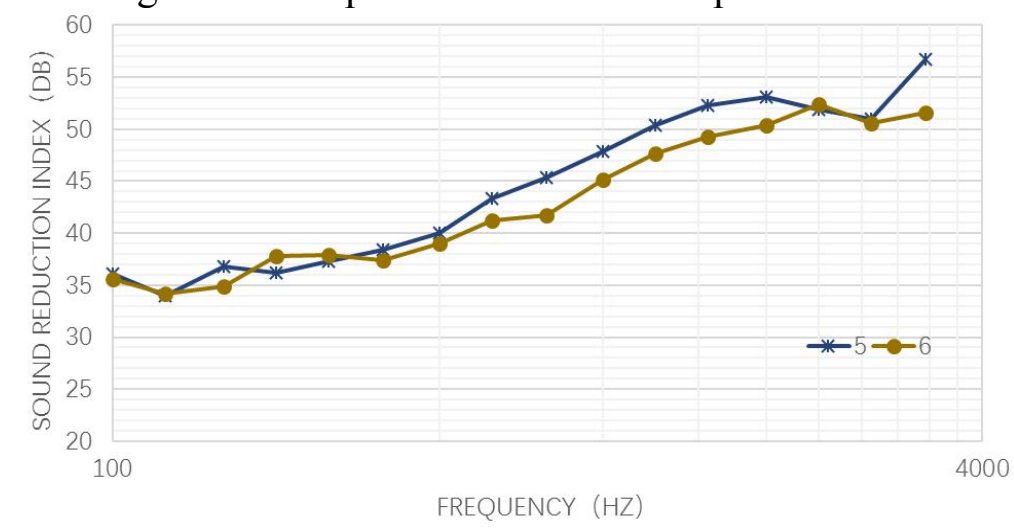




\section{Conclusions}

I. Double-sided mortar changes a single material wall to a multi-material wall and help improving acoustic performance in the medium and low frequency region.

II. ALC broads perform worse than Bricks because ALC has lower density, which is the most important influence factor in medium frequency region.

III. Steel frames are usually thought to be non-sound insulation for the reason of acoustic bridge, therefore forms of acoustic control are needed and proper practices can significantly improve the acoustic performance of steel frame.

IV. Increasing the stiffness of materials will improve the sound reduction index particularly at low frequency.

V. Resonant effect and coincidence effect are inescapable. What we can do is to move the coincidence dip to the higher frequency region and make the resonant frequencies lower. Details will not be carried out in this article.

\section{Acknowledgements}

This article is financially supported by China Construction Steel Structure Company and get technical support from Tianjin University.

\section{References}

[1] C.J. Clark, D.O. Elias and R.O. Prum: Journal of Experimental Biology, 2013, 216(18):3395-403

[2] Carl Hopkins: Sound insulation. Elsevier, Butterworth-Heinemann, 2007.

[3] M.W. Simons, J. R. Waters: Sound Control in Buildings. A guide to Part E of the Building Regulations. Blackwell publishing, 2004.

[4] Information on http:// http://www.steelconstruction.info/Acoustics

[5] GB 50118-2010. Code for sound insulation design of civil buildings.

[6] GBJ75-84. Code for sound insulation measurement of buildings.

[7] DF Education: Building Bulletin 93, Acoustic Design of Schools. Department for Education, The Stationary Office, 2003. 